\title{
Rites of passage through talent management progression stages: an identity work perspective
}

\author{
Carole Tansley
}

HR Division, Nottingham Business School, Nottingham Trent University, Nottingham, UK.

Susanne Tietze,

Sheffield Business School Sheffield Hallam University, Sheffield, UK.

Corresponding author: Carole Tansley carole.tansley@ntu.ac.uk

Carole Tansley is Director of the International Centre for Talent Management and Leadership Development and Head of Professional Doctoral Programmes at Nottingham Business School, Nottingham Trent University. She is an HRM specialist and an authority on talent management and the development of global electronic HRM (e-HRM) systems. She leads a team of applied researchers engaged in studying innovations in human resource and talent management strategy, policy and practice. She has published in leading journals such as: British Journal of Management, Management Learning and the Journal of Managerial Psychology.

Susanne Tietze is Professor of Organisation Studies at Sheffield Hallam University, Sheffield Business School, UK. She is a linguist by training and an authority on language and organizations. She has been awarded MBA and PhD from Sheffield Hallam University and MA in English and German from Karl-Ruprechts-Universität, Heidelberg (Germany). Her research focuses on language and discourse as used in work contexts and she has conducted studies on emergent forms of work organizations. Her book, International Management and Languages (Routledge), establishes the relationship between two orientations - social construction and linguistic relativity - and demonstrates how they can be drawn on to frame and understand the activities of managers. She has published in leading scholarly journals such as Organization Studies, Journal of Management Studies and Journal of Business Ethics. 


\title{
Rites of passage through talent management progression stages: an identity work perspective
}

\begin{abstract}
Our aim in this paper is to examine the experiences of organisational 'talent' as they advance through progressive stages of a talent management programme and to identify ways in which identity work plays a major part in such transitional processes. A case study is presented examining the experiences of accountancy professionals ('talent') in a global management consultancy as they progress through 'rites of passage' at different levels of a talent management programme. Findings firstly show that successful transitions through such rites of passage are the necessary precursors to talent advancement. Secondly, that the exercise of identity work is a concomitant part of specific phases of such rites of passage (separation, liminality and incorporation). Thirdly, that, particularly at the most senior management levels, 'appropriate identities' in line with normative assumptions of the organisation are required to be developed and displayed. Finally, that such progression is characterised by being in ambiguous and fluid relationships and contexts, which need to be overcome in an on-going process of talent advancement. Lessons are drawn for the design of talent management interventions that take identity work into account.
\end{abstract}

Keywords: talent management; talent advancement; rites of passage; liminality; identity work; talent pool. 


\section{Introduction}

Talent management is comprised of strategies and protocols for the systematic attraction, identification, development, retention and deployment of individuals with high potential who are of particular value to an organisation (Tansley and Sempik, 2008). Talent management strategies are geared towards the attraction of talent from inside and outside the organisation, with their development and retention taken as key to enabling sustainable competitive advantage in a global knowledge economy (Cappelli, 2008; Scullion and Collings 2010).

Much of the extant research on talent management to date has been at organisational level, focusing on the structural aspects of talent management strategies (Mäkelä, Björkman and Ehrnrooth, 2010), as well as the systems and diagnostics which are available for practice (Berger and Berger 2011; Tansley and Sempik, 2008). Although some studies do consider talent management at the individual level, such as how 'talent' is defined in organisational practice (Tansley, 2011), there is little consideration of how talent management strategies and protocols are experienced and responded to by talent at different stages of the organisational talent management process (Huang and Tansley, 2012) and how these responses inform, incorporate and involve identity work by such talent. Our objective in this paper, therefore, is to extend the talent management literature to incorporate an identity-based approach by linking with some anthropological literature and concepts.

In particular, we draw on rites of passage (Van Gennup, 1960) as an analytical frame to understand the identity work required by individuals at different stages of the talent management process. This term drives from Van Gennup's study of the rituals of social groups where he demarcated the 'passage', or ways in which a person moves, from one social grouping to another '(e.g. boy to man, girl to bride)' (Beech 2011, p. 287). This informs our two research questions: 'What constitutes rites of passage across successive levels of a talent management programme?' and 'What is the role of identity work in ensuring successful advancement through each talent management rite of passage?'. To address these questions we focus on consultancy staff in a global accountancy practice and investigate how talent management, as framed and articulated by senior management, is essentially comprised of such 'rites of passage' as they enacted via talent management practices and protocols, in different geographical locations, at hierarchical levels by individual talent. 
In the next section of the paper we consider how organisational talent, both individual and communal, has been defined in the literature, and then explain how progression through a talent management programme can be usefully construed as 'rites of passage' for those regarded as organisational talent before moving on to discuss the concept of identity work. We then describe methods of data collection and analysis and present our findings, structured by providing an overview of the different talent management rites of passage employed by 'The Firm' and the experiences of their talent. Our discussion highlights how successful talent advancement is contingent on the development of 'appropriate identities' and how identity work is central, if less visible, in this.

\section{Identifying organisational talent: as individuals and 'communitas'}

Talent has been defined in organisational studies as 'those individuals who can make the greatest difference to organisational performance, either through their immediate contribution or in the longer term by demonstrating the highest levels of potential' (Tansley and Sempik, 2008). Given the focus on individual high performance linked with high potential, it can be argued then that talent needs to be at the strategic core of the organisation, as only they can both deliver existing high-quality services as well as act as innovators of product and service portfolios. Talent management projects capture talent not only at the individual level, but also as a collective. Many organisations use a structured, stage-based hierarchical approach for talent advancement and there is also a strong element of 'staggered process', which is the basis for the collective experience of talent management. At the collective level global organisations tend to operate 'talent pools' as part of their overall talent management strategy (Mäkelä et al., 2010). Being in a talent pool provides a 'communal experience' ('communitas') as the talent pool is a collective of employees with particular characteristics set by the organisation and who have been recruited and identified as talented within the talent management review system (Tansley et al., 2007; Collings and Mellahi, 2009).

In these collective pools talent is given identity labels such as: 'entry-level talent', 'emerging talent', 'rising stars' and 'executive talent' (Tansley et al., 2007). Whatever the structure, a talent pool is designed to ensure that those with talents needed by the organisation are recruited and developed in a way that ensures homogeneity of talent availability across an enterprise. It is by passing through a series of stages with those at a lower level supported and developed to the next level that individual talent at the lower stages can be differentiated 
from talent at more senior level. In other words, the existence and functioning of talent pools is based on both a communal experience as well as on an individual experience when individual members have to pass successfully through the different structures of an increasingly selective talent supply chain in order to enter the next, more senior, pool.

At the individual level, being connoted as special, in possession of unique gifts and therefore framed as a potential future leader or senior partner of a large global corporation, provides considerable emotive appeal for those categorised as organisational 'talent' (Huang and Tansley, 2012). Thus, the talent label is a 'persuader' to join an organisational-communal experience, while at the same time being able and willing to stand out from the 'talented crowd' to establish oneself as a successful and high-performing individual. Thus, being categorised as 'talent' is part of discursively fashioning particular (desirable) identities, such as 'unique', 'gifted', 'special' and part of an 'elite' group, usually operating in the global environment (Collings and Mellahi, 2009; Scullion and Collings, 2010), so being differentiated from 'the less gifted individuals' (Alvesson and Robertson, 2006).

Engendering such complete commitment requires careful management control, both through talent management systems and protocols (such as the design and operation of 'talent pools') as well as through the cultivation and control of particular identities. For, as we demonstrate in this paper, the project of talent management not only attends to the production of visible behaviours and technical competencies, but also to the management of the 'inside - the hopes, fears and aspirations of workers' [or talent] (Deetz, 1995, p. 87). It is our contention in this paper that the individual response to this organisational activity is a continuous engagement with identity work (Watson, 2009), by which we mean the on-going processes in which human beings engage in order to form, amend, repair, strengthen or revise their identities in their respective contexts; this is particularly so for those who aspire to managerial and senior leadership positions (Sveningssons and Alvesson, 2003). We see identity work as an ongoing process, not least at moments of transition to different stages. Our analysis focuses on those situations and contexts of transition by employing Van Gennep's (1960) notion of rites of passage as an analytical lens. 


\section{Rites of passage across successive levels of talent management}

The analytical value of Van Gennep's (1960) anthropological notion of rites of passage has been recognised within organisational studies (cf. Garsten, 1999; Tempest and Starkey, 2004; Czaniawska and Mazza, 2003). We extend this use by employing the concept in the context of talent advancement through the talent management process. The additional utilisation of Turner's (1977) three stages of rites of passage, (separation, liminality and incorporation) allows us develop a more nuanced analysis.

The first stage, separation, involves a person's symbolic/physical detachment from their usual social life or status. For example, new graduates enter the first separation phase by leaving behind their social life and groups at the ritual of the university graduation ceremony in order to join the organisation and begin their progression through the talent management structure. Rites in this phase include: graduate talent recruitment and selection process, the company induction experience and the joining of an organisational 'talent pool'.

The second stage, liminality, is where a person is in a state of transition betwixt and between the first and third stages. In this stage a person will 'cross the limen (...) into a new and transitional state where the social fabric they are used to is allowed to unravel. They enter a different space and time ... radically different from the ordinary (...). The old self dies so that a new self can come into being.' (Viljoen and van de Merwe, 2007, p.11). Thus, in liminality, a transitional period is experienced, 'after they have been separated from their previous way of life but before they enter a new social category and a new way of life' (Newell, Tansley and Wagner, 2008, p.2).

Drawing from Newell et al.'s (2008, p. 6) study, we characterised liminality in talent management as having particular characteristic features, such as: temporality, ambiguity, freedom to act and being part of a community. Thus, talent are in a temporary situation at each level, understanding that they will eventually be required to move on, even though there might be a lack of clarity of where the next move will be or what the next role will involve Each liminal space is ambiguous in the sense that a person does not fully understand what is involved in their current role or the business context in which they are working. In the context of talent management, this liminal characteristic can be both unsettling or seen as an exciting way of developing. Also in the liminal condition there is freedom to express 
creativity whilst being partly unencumbered from the constraints others in more settled organisational roles experience. Finally, there is a liminal condition of communitas which binds those labelled as organisational talent together in a talent pool (whilst possibly alienating those outside of the pool).

Scholarly interest has begun to focus on the nexus between liminality and identity change (Beech, 2011; Clark, Gioia, Ketchen and Thomas, 2010, p. 399) as career stages are investigated as transitions between different identities. Ibarra, Snook and Ramo (2008) use liminality to investigate the identity work that particular 'executive staff' have to undergo in order to develop and maintain senior leadership positions and understand the process of leadership development to be the emergence of a new sense of self, where the key feature of change is a 'profound transformation in what people think, feel and value (p. 8). We extend this argument and position it within the talent management discourse as we argue that this transformation can be understood as the successful completion and overcoming of distinct 'liminal spaces' which are incorporated into The Firm's talent management programme.

The final stage, incorporation, is the aggregation of the passage through the states and is experienced by the initiated as s/he is symbolically/physically incorporated into their (new) existence in society (or organisation) as a different person. In talent management rites of passage, incorporation is experienced as the initiand is symbolically/physically incorporated into their existence as 'organisational talent' at a particular transition stage and here the changes in identity of the 'emerging talent' in the next stage are first felt.

We propose that using conceptual vocabulary from the anthropological and organisational literature on rites of passage provides a useful heuristic device to unravel the relationship between identity work and talent advancement in the context of a large, global organisation and its talent management strategy.

\section{Research Methods and Analysis}

Our methodological aim for this study was to build theory in the area of talent identity work using a grounded theory approach (Glaser and Strauss 1967; Locke, 2001, p. 103) to better understand unexplored subtleties of rites of passage of accountancy consultancy talent, thereby extending current work in talent management research and refining work on rites of 
passage and identity. Our research method is a case study of an organisation we are calling 'The Firm', a major accountancy consultancy with a corporate strategy of being the leading professional firm in the different markets they chose to serve. The Firm attracts and retains more than 140,000 of 'the brightest and the best' accountants and other professionals to work as finance consultants on industry-focused services in their offices in 149 countries.

\section{Rationale for Case and Sector Selection}

The Firm was part of a larger case study research programme of nine organizations undertaken between 2006 and 2008. This research programme investigated the definitions of talent management within diverse organisational contexts and how they were interpreted and implemented in practice. The sample was aimed at being broadly representative of the types of organisation which would operate talent management programmes at the early stage of development in the UK. Selection criteria was to attain a spread of organisations from the public, private and not-for-profit sectors, being of different sizes with regard to employee head count.

\section{TABLE 1 HERE}

The rationale for choosing case study nine for this paper is three-fold. Firstly, little is known of the challenges of managing consultancy talent through individuals' 'cycles of experience'. Secondly, issues relating to transition between different stages of talent management were common across all cases, but there was specific evidence at each stage of talent management with case study nine, so therefore it was considered that this case study would be particularly relevant. Thirdly, the financial services sector has been at the forefront of implementing career advancement systems embracing 'talent' as a key aspect (ACCA, 2006) and provides an opportunity to understand a relatively 'mature' approach to talent management.

\section{Limitations}

This empirically-based case is a 'construction of certain elements of reality in a logically precise configuration' (Gerth and Mill, 1948, p. 249), together with the use of conceptual vocabularies taken from anthropology, from talent management discourse (e.g. talent pools, talent stages) and the words and concepts used in the field (e.g. rising talent, emerging 
leaders). This combination of empirics with conceptual tools enabled us to construct an account which balances case idiosyncrasies with transferable insights.

At the same time, The Firm is a particular consultancy firm, positioned in a particular sector. This imposes certain limitations on our study, i.e. to what extent findings can be transferred to other sectors or settings in an unproblematic way. Analysis of consultancies (e.g. Alvesson and Robertson, 2006; Czarniawska and Mazza, 2003) have shown them to be particularly useful examples for unpacking the unarticulated, implicit assumptions which underpin the formation of relationships and career advancement. As our study, too, focuses on 'unpacking less immediately visible aspects of talent management/career advancement', our findings add to the understanding of 'what underpins' such initiatives. Its location in the consultancy field is therefore appropriate and in line with our overall research intent. However, any assertions we make in the discussion or conclusion are mediated by pointing to the specific context of our empirical study.

There are further limitations in this study. Because it was part of a wider research programme considering enactment of talent management in the case study organisations, we had preconceived notions of stakeholders and this meant there were gaps in data gathering for triangulation. For example, we only interviewed those who were regarded as organisational talent and selected for us by the Talent Director. It was hardly surprising, therefore, that we did not have any derailleurs or rejected employees from the talent management programme in our list of interviewees. Also, our sample does not provide insights into gender, age or ethnicity, for example. Neither did we include mentors, who emerged as having an inordinate effect on individual talent making poor advancement decisions. We take these points forward in the future agenda for research in the conclusion.

\section{Data Collection}

The empirical material for this paper was collected in 2007 and taken from company documentation (e.g. Annual Report; webpages), semi-structured interviews $(\mathrm{N}=6)$ of one hour of those staff responsible for management talent (Talent Director, Human Capital officers, Head of a business and business HR partner) and two focus groups $(\mathrm{N}=12)$ of 90 minutes with staff at different career levels regarded as organisational talent held at The Firm's corporate headquarters in London. The same protocol used for the other case studies 
was also used here, with three main research questions: how do the organizations in different sectors define 'talent'? how is talent management practiced as part of the corporate planning process? and how is organisational talent nurtured? (Tansley et al., 2007; 2008). Examples of themes the focus group members were asked to reflect on were: their formal and informal learning as they experienced the management practices and assumptions of each stage of talent advancement; any difficulties they encountered when preparing for progression into the next talent pool; the role of mentors, senior colleagues and peers in terms of informal learning and engaging in technical curricula and any careers advice received. Although we did not ask about age or race, it appeared that most participants were between the ages of mid-twenties to early-forties, with most being white and gender being equally split. We acknowledge a certain bias in our data and have articulated a need for gender and ethnic-specific studies in our agenda for future projects. The focus group context enabled us to engage with individual talent and to stimulate and observe interactions between them; thus allowing the authors to tease out differences and commonalities in perspectives.

All sessions were taped and later transcribed verbatim and both interviewers took notes, thus generating around 110 pages of transcripts and field notes. All notes, transcripts and documents were collated into a qualitative research database, NVIVO9.

\section{Analysing the Data}

The first interview transcript analysed was that of the talent director who gave us a clear understanding of the way in which the talent management process was set out in relation to career levels in the organisation and the nature of the talent pool constructed at each level. Emerging from this analysis was that this design provided for organisational talent taking part in cycles of experience, which we identified as rites of passage. The transcripts of the other officers and managers involved in the talent management process confirmed this assignment. On analysing the transcripts from organisational talent it emerged that the second phase in each rite of passage, that of liminality, was the one most focused upon by interviewees. We then iteratively worked back and forward between the research material and the emerging structure of theoretical arguments (Locke, 2001), increasingly identifying patterns of identity work and identity statements, which demonstrated to us a shift of control (of behaviour, attitudes to work, dispositions and relationship) from the outside (as structured programmes of training and assessment) to the inside (as wholly accepted norms and values). Before 
reaching theoretical saturation, we also re-examined prior studies of talent management, rites of passage and liminality and, through theory comparison and iteration (Orlikowski, 1993), we were able to identify and highlight the uniqueness of our new theorizing and how it related to the 'liminality talk' of talent management stakeholders and talent liminars. We selected data for inclusion in this paper that is representative of the liminality talk (i.e. quotes that point to the coping with ambiguity; the internalisations of norms as the basis for making 'good decisions') and we also included data from different talent pools.

\section{Case Study: The Firm}

The Firm operates an enterprise-wide talent management programme with the aim of enabling their accountancy professionals to "draw upon their knowledge and skills to: help shape industry, encourage activity in local communities and rebuild public trust in corporate reporting' (The Firm's Annual Report). Key drivers for talent management are firstly to address the demand from clients for consultants with the right skills and, secondly, to address development requirements of all staff. The Firm recruits around 1000 graduates a year to join their bank of consultants engaged across their accountancy, tax and assurances businesses. The Firm's employment culture for professional talent shows a similarity to the four consulting firms based in the UK and Sweden examined by Alvesson and Robertson (2006) whose senior management had constructed an elite organizational identity with a 'neoliberal' form of governance. Once attracted to the organisation, consultants are trained to be trusted to act and behave in the interests of the firm, to engage in self-discipline which sustains a desire to accomplish high performance standards and to present a professional image that retains clients.

\section{How talent is identified in 'The Firm'}

There is a very clear institutional identification of talent in The Firm, which is both inclusive (everyone is talent) and communitas-based (talent pools), but which is also exclusive as key talent/key people are to be identified and developed in different ways from the 'everyday talent'. This was expressed by the Talent Development Director as below: 
'Talent' in The Firm means two things. One, I think that everybody in The Firm accepts that everybody is a talented individual. We recruit bright people intellectually. But our business also has the responsibility to try and help them realize that. So... there is a fundamental belief that everybody is talented, and there is a belief that we do need to identify future leaders or people who are going to lead key parts or have key roles in the business in the future and these would be quite senior roles. And that identifying talent in those spaces, and helping people gravitate towards one of those roles, will be the key challenge for us.

In order to address this 'key challenge', The Firm has developed a staged talent advancement system to manage talent from recruitment to the most senior stages in a controlled manner through a talent pool approach. It is within this system that successive rites of passage can be identified.

\section{Rites of passage across successive levels of the talent management programme}

The Firm recruits highly educated graduates into their level one talent pool. Talent is expected to advance through the ranks, successively joining Leadership and Talent pools such as 'Rising Talent' (new graduate recruits from university), 'Emerging Leaders' (having become fully qualified accountants) and 'Next Generation Leaders' (employees who have the potential to lead a substantial and complex business in the future). Talent at a certain level will join the appropriate pool no matter what geography or business an individual is in. The Talent director drew a picture of The Firm's Leadership Model (see figure 1) used by all businesses and functions to assess their talent and demonstrating how talent advancement is related to appropriate learning and training interventions:

\section{FIGURE 1 HERE}

In the next section we track the experiences of individual talent in different talent pools.

\section{Rites of passage at talent level one: 'Rising Talent'}

Rising talent are recruits from university who are put in the first talent pool and undergo an intense period of training, work assignments and examinations. 
When I got the interview with The Firm I was thrilled. The Firm is well-known as a brilliant employer. At university I was at the top of our group with two others. We always did well in exams ... you know, top of the class and all that. ... Two of us got jobs with The Firm and away we went. It's been terrifying really. Such a difference to university, so many rules and regulations and you have to work so many hours just to keep up.

I'm managing but my friend is struggling a bit. We're both working on what they call a 'stretch project' at the moment, which is hard, especially with all the studying we have to do, too. I'm loving it, but she's miserable and anxious all the time. I keep telling her it's only temporary and we'll soon pass through this, but sometimes she gets stressed to the point of hysteria!

It's near the end of the project and we're doing assessments on capabilities and competencies and having conversations with managers about where we go next. I've asked for the Media Technology Division because the work looks exciting and you get to go abroad to places like New York and Australia. She says she is going to apply for a post at the office in Newcastle looking after public sector clients. She says she thinks she'll be happier there.'

\section{Rising talent; Focus Group}

First, the participant refers to the separation from university life to the more demanding (rule regulated; long hours) and challenging life of a new recruit to The Firm where he is immediately identified as 'Rising Talent'. The ability to cope technically is demonstrated through rites in liminality, such as being allocated to 'stretch projects', and the passing of assessments. However, in the same vein, Rising Talent is tested in more than a technical sense as only quite robust individuals can manage the stress and pressure to move out of this transitory and temporary stage, where incorporation is characterised by the taking on of a different identity (different from being a student) of a hard-working, geographically flexible and adventurous young professional. Second, this is not a transition that is easily achieved as the 'friend' struggles with the pressure, chooses a 'less adventurous next career destination' and not only comes out of the transition in a less than victorious way, but is also jeopardising 
her future advancement up through the talent advancement levels. At this stage rites of passage are experienced by leaving university, establishing oneself as part of a (talent) communitas - and becoming a successful member with certain outlooks on work and career destinations. Third, this is achieved by demonstrating technical competency (through the passing of exams) as well as the development and expression (through the choices one makes) of particular dispositions and attitudes.

\section{Rites of passage at talent level two: 'Emerging Leaders'}

Rising Talent who have gained their accountancy qualifications move forward to the next career level, 'Emerging Leaders', and enter another stage of talent advancement. They continue with their technical development (some study at Master's level, such as MBA) and there is also a company-agreed "Seven Competences Framework" which they work towards in order to advance to more senior roles.

Yes, it is a statement of seven core competencies which at the moment are the benchmark against which people are measured for a variety of roles as they go forward. They are a statement of what I would call 'price of entry'. So talented people have to have a relatively good level of expertise against these competencies, absolutely. But if we are looking for leadership and we are looking for 'something different', that is not embodied in a competency.

Talent management director

Talent entering this level are still students, but they also have to strengthen their identity as consultants in The Firm, so separation is less stressful than in the first stage. Liminality at this talent level involves individual talent in identity work to change from being seen as more than just competent/experienced accountants. The institutional requirement has therefore changed from just requiring technical expertise to developing behavioural and leadership competencies (something different), which are harder to capture within the definitional confines provided by the vocabulary of competencies.

In the early phase of entering this liminality stage, talent pool members have to have a relatively good level of expertise against these competencies; then once mastered, other 
attributes are majored upon, such as adaptability, willingness to be flexible and take on challenging tasks. These 'qualities' are less easily articulated and captured in the generic accountancy profession competencies; yet, their cultivation becomes the increasing focus of the talent management process in the more senior stages such as Next Generation Leaders.

At the end of this liminality phase, as they enter the incorporation phase, accountancy talent need to demonstrate they have learned to manage the ambiguity, requirements for flexibility and the temporary nature of their activities in a consultancy role:

Consulting can be quite varied - sometimes you find yourself on just one project for as long as a year and other times you have a series of shorter projects. Both are good in different ways - I've recently had more of the latter, having been on three different projects over the past 3 months. After a long project it's nice to be back to a challenging variety of roles again where you only have a couple of days to get up to speed before you have to start delivering. [The Firm] gets quite festive over Christmas - the giant tree, the carol singing, the Christmas drinks and meals. Unfortunately I have to get a report in for Christmas Eve, so I'm working right up to Santa arriving but then having a week off to rest and hopefully recover from a busy year. 2009 is starting to look quite busy already so I think I'm going to need it...

Emergent Leader talent, company blog entry

This Emerging Leader is nearing incorporation stage. We see evidence of identity work in relation to the demonstration of appropriate behaviour and the development of an appropriate identity as committed, engaged consultant. Long hours are no longer viewed as a problem to be coped with, rather, they are presented as a given. As this newly-fledged consultant is emerging from liminality she has understood that an appropriate identity for her is to be seen as a 'play hard, work hard' individual who can manage her own time, does not moan and just 'gets on with it'. In this expression of being a full member of the Emergent Talent communitas she has demonstrated that she has successfully passed the incorporation progression test, i.e. the price of entry has been paid. 


\section{Rite of passage at talent level three: Next Generation Leader}

The institutional requirement of Next Generation Leader talent is to be looking for leadership, something different beyond [accountancy and consultancy] competency' (Senior manager), with the focus more about having a particular disposition, the cultivation of particular outlooks and values, that is, being the 'appropriate individual' for accountancy consultancy leadership. Here, the rites of passage which help The Firm align organisational and individual needs relates to talent passing through an individualised, structured performance management process which allows regular feedback and enables, when appropriate, speedy mobility between businesses, roles or tasks. With development at the more senior level, mentors and coaches are seen as important elements of this executive development:

The mentor role varies across our business. Some people will have structured mentor schemes, which I think are less effective. You should have a mentor, you should explore who your right mentor is, you should be self-starting. It is not necessarily one mentor. I have four or five mentors. Depending on the circumstances or the situations I am in. They are a disparate group. I could list the people I talk to today but they might not be the same people I would talk to later on this year or next year.

\section{Executive Head of Business}

Interestingly, this Executive Leader, presenting the institutional voice, describes the requirements at this stage in almost purely normative statements (you should find a mentor; you should be self-starting), based on a mind-set which is self-starting and able to make individual choices in the line with strategic requirements.

This self-starting mentality is confirmed by one Corporate Next Generation Leader:

I think it is very much a case of your development... is really your own development and therefore you have to take a large degree of ownership of that and to a large extent when you have gone through levels one to three, you are kind of driven along a path while you are doing a qualification or you are doing tax or whatever, but 
thereafter you have to decide what to develop yourself, and the qualifications you want to pursue or what other experience you want to get. It's freeing, being unrestrained like that.

\section{Senior manager}

The provision of mentors in talent development is a common feature, not least because of the senior level of those in the upper career level talent pools. However, difficulties can arise when advice taken from mentors hampers progress:

I was really happy to get the offer from The Firm after getting my degree. The early years were great... loads of challenging projects and really great training. Of course, when I joined I was part of the talent pool - well we all were - and we all got on really, really well ... at work and the social life was great as well. Then I was working on a project in the Scottish office and was offered an early promotion [to Next Generation Leader level]. The others [in the Emerging Leaders' pool] were quite jealous [laughs]. It was a couple of steps up and the money was amazing and I had a great affection for Scotland ... the highlands and all that were great for being outdoors, which I love. Anyway, taking advice from my mentor I said yes, and for a while I was really happy with the way thing were.

\section{Partner; Focus group}

The key point of this story is that an individual had been identified as a special talent and gained early promotion. In principle, this promotion signals the successful transition to the next stage. However, this selection as 'super-special' proved to be problematic:

What I hadn't realised though was that the move had taken me out of the [Emerging Leaders] talent pool too early and, of course, being up there and out of London I wasn't in [the Next Generation Leader pool either, so not in] the line of sight for any promotions after that.. I was really annoyed at myself for not thinking the move though ... . Someone said to me 'if you want to move on in your career, you've got to get back here'. So I applied to come back and got back eventually but I missed Scotland and had forgotten what a hell-hole London can be. It was also difficult to get 
back into the systems, the politics and all that here in the London [corporate] office. It was an anxious time to start with. I'm OK now I'm linked in with my old friends. Time will tell how it turns out [laughs].

\section{Partner; Focus group}

The promotion took her out of the talent pool 'communitas', both in terms of her peers, but also geographically and it propelled her into a different liminal geographical and emotional space, which (whilst attractive to her) proved to be detrimental to her status in the talent management programme as a 'Next Generation Leader'. In other words the liminal space had become individual rather than communitas based; this example provides some evidence that the collective continues to play a role in talent advancement as the talent management process needs to be balancing the requirement to identify 'special and creative talent', whilst ensuring that it continues to be bound into collective and institutional networks. The identity work focused on repairing (in her own eyes and in those of the communitas) the relationship with the institutional power structures by realigning herself with corporate structures. Physically, this work manifested itself in her decision to relocate, despite having a different 'private' identity, which is not located in the urban environment and corporate values.

\section{Discussion}

The advancement through successive levels of talent management is achieved by talent passing successfully through a series of rites of passage, such as involvement in 'stretch projects', passing of professional exams, undertaking Masters qualifications and through discursive interactions between talent peers, managers and mentors. Such rites locate 'talent' in temporary, ambiguous situations where they have yet to master the rules of engagement for subsequent stages and achieve 'full membership' of the most senior group. This process involves separation, liminality and incorporation by talent at each level, with talent engaging in a high level of identity work, particularly when experiencing, and coping with, 'liminal situations'. In this regard our analysis of talent liminality demonstrates that the relationship between 'talented staff' and the organisation is not an articulated, stable and unambiguous one, but is rather that talent advancement (or lack thereof) is identified as a communitas experience for individuals experiencing not only a feeling of freedom, but also an on-going 
process of addressing and resolving temporary and ambiguous positions, not least through successful completion of rites of passage.

All of these insights help us with our deliberations in answering our two research questions:

\section{Question 1: 'What constitutes rites of passage across successive levels of a talent management programme?'}

Rites of passage at talent level one, (Rising Talent) are experienced as young graduates, all with good grades, are required to transform themselves, within communitas (i.e. talent pool), into young professionals. In order to do so, as liminars they have to engage in temporary 'stretch projects', which gives them freedom to test their technical competences as well as their ability to develop emotional and mental dispositions to cope with ambiguity in the form setting priorities for conflicting demands, deadlines and requirements. Their freedom is limited in other ways, as they also have to adapt to a corporate regime of structures, protocols and processes which are alien to them. Following the passing of professional exams and the successful completion of their stretch projects, they reach incorporation stage, through transformation into young and aspiring professionals. Identity work at this stage is associated with the ability to become a person who is technically competent; emotionally resilient and ambitious in their choice of their next career destination (New Castle or New York!). Liminality is experienced as emotional challenge, a test of their technical expertise and successful transition talent development interventions is evidenced by passing examinations and by embracing a life of (geographical) flexibility for informal, experiential learning.

In rites of passage at talent level two (Emerging Leaders), education and training interventions continue to be the preferred talent development interventions for the talent communitas, with a temporary focus on the achievement of (Masters) degrees, successful incorporation and benchmarking against corporate core competencies. Yet, at the same time, The Firm looks for something which is difficult to capture in competencies. Here again, ambiguity is evident in the limins, which is about being between clearly defined structures and frameworks against which 'talent' will be assessed and a less well defined 'difference'. This 'difference' is best expressed as an 'attitude and mind-set' which embraces the freedom to choose attractive projects, whilst incorporating a long hour culture and the demands of a tight schedule driven by deadlines; i.e. the development of an internal disposition which enables an 
individual to supersede culturally significant days (such as Christmas Eve) with the driving imperative of finishing a work task.

In rites of passage at talent level three, the take-up of (structured) mentoring and coaching programmes is a means of developing 'advanced talent'. Development rites are still of a temporary nature. The nature of communitas changes as the focus for development becomes focused on the individual rather than the talent pool. The strong normative statement of an Executive Director points to the corporate preference that individual talent should be selfdeveloping and self-initiating in the choices they make about who should mentor them and what kind of training they may need. Here, liminality as an ambiguous state of being has become on-going and is experienced as liberating and freeing as 'structures, frameworks and programmes' do not substitute for the self-determination of individual agent/talent, who is now able to make appropriate choices about their career moves and developmental needs. Clearly, if such choices are premature and not grounded in existing networks and constellations, individual talent has to make amends and take appropriate steps to make up for 'bad' choices. Identity work in stage three, and certainly when leading up to stage four, is not contained in structures or pre-described frameworks; it is about developing an internalised outlook where flexibility, self-determination and the will to succeed are not externally controlled, but based on internalised dispositions developed over several years of being part of a talent management supply chain. We can see the full picture of our analysis in table 2, below

\section{TABLE 2 HERE}

Question 2: "What is the role of identity work in ensuring successful advancement through each talent management rites of passage?",

Technical capability on its own it is not sufficient for successful progression through the talent advancement process. Negotiating passages successfully requires talent to make 'correct' decisions about the centrality of work in their life and the relative importance of work task and private tasks. This requires talent to engage in identity work in Watson's (2009) sense of continuously redefining relationships and values. Without readjusting their identities through undergoing rites of passage and their different stages, the realignment from talented graduate, to young professional, to senior consultant to leader, could not happen. 
Identity work is concomitant to career advancement as a necessary, if invisible, aspect of talent development.

In this process individual talent must be able to create a balance between integrating itself into the values of its respective communitas while also ensuring that it is continued to be seen as 'special' and 'unique'. This potential tension can only be reconciled by demonstrating high performance in rites of passage (e.g. in examinations and achieving competencies), while embracing collective communitas values by making the 'right choice' (e.g. about career assignments, career location or prioritising work over private preferences). This is particularly so in the earlier stages where both ability to perform as well as desire to conform are continually 'tested, not only through formal examination and assignment structures, but also through discussions with peers and managers.

Progressively, norms and values of the corporation are internalised and identities that are resilient, yet flexible; self-reliant, yet responsive to corporate values and expectations are developed. The identity work here relates to the rationalisation of the self as free and liberated, which enables individual talent to accept temporality of assignments and relationships and to embrace ambiguity as the ontological state of being the world. Liminality as the 'betwixt and between' state of being is accepted as the perpetual way of living and working. Identity work focuses on the development of a strong sense of self; a self which is able to cope with, indeed celebrate, perpetually shifting assignments, relationships and locations.

Identity work is central, if invisible, to the achievement of career advancement and to the successful and continued integration of individual talent into the collective communitas and the overall organisational purpose. In engaging with identity work, individual talent develops outlooks and dispositions which enable it to cope with sometimes conflicting preferences (e.g. between private and work commitments).

\section{Conclusion}

The empirical analysis of talent management in a global consulting firm has shown that talent advancement is rooted in the development of technical expertise and the development of particular dispositions and work orientations, which require the development of identities 
which enable individuals to cope with continuing contexts of ambiguity and change, with the ultimate goal of becoming part of the organisational elite and leadership (Alvesson and Robertson, 2006). There are both high rewards to be gained and high costs to be paid (stress; sacrificing private time; cutting emotional attachments to people and landscapes) when becoming a successful corporate talent - and the 'costs' can perhaps only be accepted on the basis of a strong sense of self, which is located in the more senior levels of the corporate world. As Czarniawska and Mazza (2003) show in their study of 'consulting as a liminal space', senior leaders or consultants have to cope with career-related identity issues where usual orders and practices are suspended, with consultants accepting liminality as an ever present routine condition and considering it to be a 'a stable state' (p. 286).

The study's insights point to the role of regulated behaviour and self-discipline on behalf of the 'talented individual'. Talent have to connect deeply and meaningfully with corporate norms and values (the internalisation process as described) in order to remain 'connected' to the communitas/organisation; yet at the same time they have to be able to disconnect (from locations, relationships, work groups and colleagues) quickly and determinedly. Finally, while senior and executive talent have to cultivate a sense of independence and an ability to challenge received wisdom, it remains unclear whether and to what extent talent management programmes allow room for critical self-reflection and the ability to challenge the ethicalmoral norms of corporate engagement.

There is a paradoxical aspect in this process (to be both able to connect and disconnect at the same time) and the notion of 'liminality' provides a conceptual means to appreciate the ontological disposition that (senior) talent have to develop in order to avoid perpetual identity conflict and struggle (Ibarra et al., 2008). Our argument is that the inherent ambiguity of consultancy work, together with the demands of talent leadership, need to be mediated by the development of distinctive identities. In the context of the consulting industry and other knowledge-intensive firms (Alvesson and Robertson, 2006) behaviour needs therefore to be normatively regulated as our analysis of liminality and talent management has shown. Thus, understanding identify formation as part of talent management is not a nebulous side-show to the emerging field of talent management; rather, an understanding of these processes sustain and underpin the performance and competitiveness of knowledge-intensive firms is central to the talent management initiative and body of knowledge. 
In the light of the findings of this study, a future research agenda could focus on exploring the nexus of ties between the formation of identities and decision-making behaviour; between individual talent identity work and corporate or communitas based identities; between the role of self-doubt, critical reflection and progression through talent pools; and between the influence of gender and ethnicity on talent management programmes.

\section{References}

ACCA. (2006), 'Insights series: Talent Management in the Finance Profession. Global Survey Report', London, ACCA.

Alvesson, M., and Robertson, M. (2006), 'The Best and the Brightest: The Construction, Significance and Effects of Elite Identities in Consulting Firms', Organization, 13, 2195 2224.

Beech, N. (2011), 'Liminality and the Practices of Identity Reconstruction', Human Relations, $64,285-302$.

Berger, L. A., and Berger, D. R. (2011) The Talent Management Handbook: Creating a Sustainable Competitive Advantage by Selecting, Developing, and Promoting the Best People, New York: McGraw-Hill.

Cappelli, P. (2008), Talent on Demand, Boston, MA: Harvard Business School Press.

Clark, S. M., Gioia, D. A., Ketchen, D. J. Jr., and Thomas, J. B. (2010), 'Transitional Identity as a Facilitator of Organizational Identity Change during a Merger', Administrative Science Quarterly, 55, 397-438.

Collings, D., and Mellahi, K. (2009), 'Strategic Talent Management: a Review and Research Agenda', Human Resource Management Review, 19, 304-313. 
Czarniawska, B. and Mazza, C. (2003), 'Consulting as Liminal Space', Human Relations, 56, 267-289.

Deetz, S. (1995), Transforming Communication, Transforming Business: Building Responsive and Responsible Workplaces, Cresskill, NJ: Hampton Press

Garsten, C. (1999), 'Betwixt and Between: Temporary Employees as Liminal Subjects in Flexible Organizations', Organization Studies, 20, 601-617.

Glaser, B. G. and Strauss, A. (1967), The discovery of grounded theory: Strategies for qualitative research, Chicago: Aldine.

Gerth, H. H., and Mill, C. W. (1948), From Max Weber: Essays in Sociology, London: Routledge.

Huang, J., and Tansley, C. (2012), 'Sneaking through the Minefield of Talent Management: the notion of Rhetorical Obfuscation', The International Journal of Human Resource Management, 23, 3673-3691.

Ibarra, H., Snook, S., and Ramo L. G. (2008), Identity-based Leader Development, Working Paper, INSEAD, Fontainebleau CEDEX.

Locke, K. (2001). Grounded Theory in Management Research, Thousand Oaks, CA: Sage.

Mäkelä, K., Björkman, I., and Ehrnrooth, M. (2010), How do MNCs establish their Talent Pools? Influences on Individuals' Likelihood of being Labelled as Talent?, Journal of World Business, 45, 134-142.

Newell, S., Tansley, C., and Wagner, E. L. (2008), 'The Liminality Associated with Project Teams: Exploring and Explaining Some of the Problems of ES Project Implementations', European Conference of Information Systems, University of Galway, 2008 Proceedings, Paper 63. 
Orlikowski, W. J. (1993), 'Learning from Notes: Organizational Issues in Groupware Implementation', The Information Society, 9, 237-250.

Scullion, H. and Collings, D. G. (eds.) (2010), Global Talent Management, Abingdon, Oxon: Routledge.

Sveningsson, S., and Alvesson, M. (2003), 'Managing Managerial Identities: Organizational Fragmentation, Discourse and Identity Struggle', Human Relations, 56, 1163-1193.

Tansley, C. (2011), 'What Do We Mean by the Term “Talent” inTalent Management?', Industrial and Commercial Training, 43, $266-274$.

Tansley, C., Foster, C., Harris, L., Stewart, J., Sempik, A., Turner, P., and Williams, H. (2007), Talent: Strategy, Management and Measurement, London: CIPD.

Tansley, C., and Sempik, A. (2008), Talent Management: Design, Implementation and Evaluation, London: CIPD.

Tempest, S. and Starkey, K. (2004), 'The Effects of Liminality on Individual and Organizational Learning', Organization Studies, 25, 507-527.

Turner, V. (1977), The Ritual Process, Ithaca New York: Cornell University Press.

Van Gennep, A. (1960), The Rites of Passage, London: Routledge Kegan Paul.

Viljoen, H., and van de Merwe, C. N. (2007), Beyond the Threshold: Explorations of Liminality in Literature, New York: Peter Lang.

Watson, T. J. (2009), 'Narrative, Life Story and Manager Identity: A Case Study in Autobiographical Identity Work', Human Relations, 62, 425-452. 
Figure 1: Talent identity progression in The Firm through development rituals (source: The Firm)

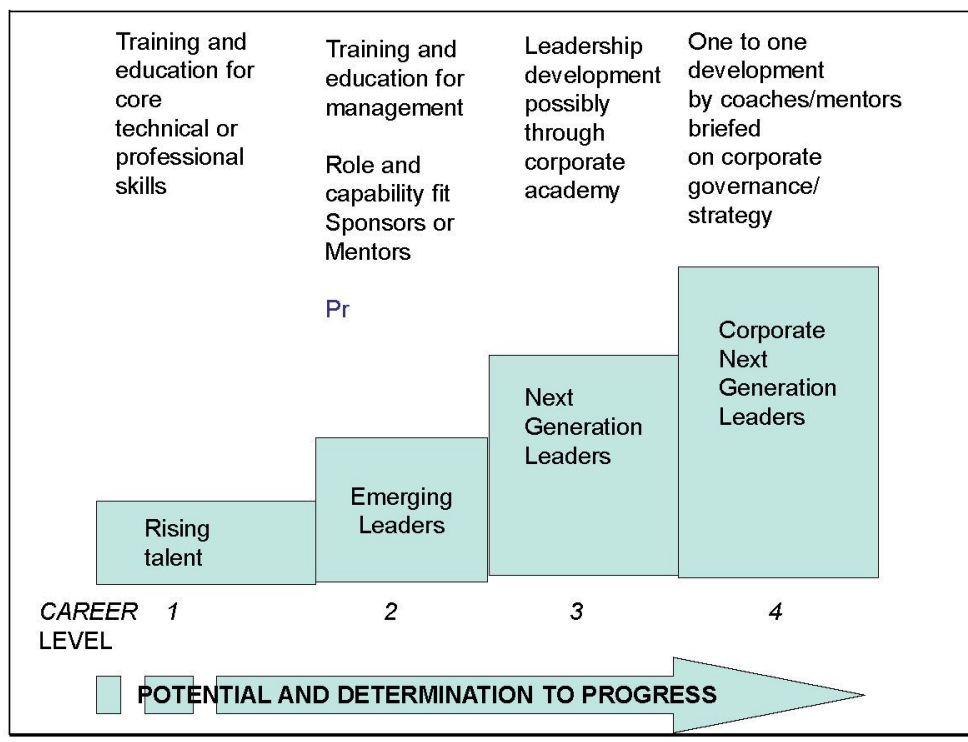




\begin{tabular}{|l|l|l|}
\hline & Type of organisation & $\begin{array}{l}\text { No. of } \\
\text { employees }\end{array}$ \\
\hline 1 & Provider of food, agricultural and risk management products and services & 149,000 \\
\hline 2 & Local authority providing services to 237,000 people. & 12,000 \\
\hline 3 & Internet site provider with 380 million unique users per month & c8000 \\
\hline 4 & Global hospitality organisation & 900 \\
\hline 5 & $\begin{array}{l}\text { A UK executive non-departmental public body to enhance access to public } \\
\text { services }\end{array}$ & 1,700 \\
\hline 6 & Housing Group (not-for-profit). & 800 \\
\hline 7 & NHS Trust serving a population of c240,000 & c5500 \\
\hline 8 & UK bank with an extensive global network & c55,000 \\
\hline 9 & Global accountancy and tax consultancy operating in 149 countries & $140,000+$ \\
\hline
\end{tabular}


Table 2: Liminality at different levels of talent advancement

\begin{tabular}{|c|c|c|c|}
\hline $\begin{array}{l}\text { Characteristic } \\
\text { features of rites } \\
\text { of passage }\end{array}$ & $\begin{array}{lll}\text { Stage } & 1: & \text { Rising } \\
\text { Talent } & & \end{array}$ & $\begin{array}{lll}\text { Stage } & 2: & \text { Emerging } \\
\text { Talent } & & \end{array}$ & $\begin{array}{l}\text { Stage 3: New } \\
\text { Generation Leader }\end{array}$ \\
\hline Communitas & $\begin{array}{l}\text { Talent } \\
\text { organisation froms } \\
\text { university } \\
\text { placement as 'Rising } \\
\text { talent' in graduate } \\
\text { talent pool. }\end{array}$ & $\begin{array}{lr}\text { Communitas } & \text { move } \\
\text { from } & \text { young } \\
\text { professional } \\
\text { accountants } \\
\text { professional consultants } \\
\text { as 'Emerging leaders'. }\end{array}$ & $\begin{array}{l}\text { Dissipation of } \\
\text { Communitas as } \\
\text { individuals move from } \\
\text { consultant to senior } \\
\text { manager or executive } \\
\text { as 'Next Generation } \\
\text { Leader'. }\end{array}$ \\
\hline Temporary & $\begin{array}{l}\text { Movement through } \\
\text { 'stretch projects', } \\
\text { examinations and } \\
\text { tests }\end{array}$ & $\begin{array}{l}\text { Examinations; } \\
\text { competencies; } \\
\text { leadership potential } \\
\text { identified }\end{array}$ & $\begin{array}{lr}\text { Individualised focus on } \\
\text { leadership } \\
\text { development through } \\
\text { mentoring } \\
\text { coaching. }\end{array}$ \\
\hline Ambiguity & $\begin{array}{l}\text { Sensemaking } \\
\text { processes impact on } \\
\text { emotional and } \\
\text { mental dispositions } \\
\text { to cope with } \\
\text { ambiguity in the } \\
\text { form of demands, } \\
\text { deadlines and } \\
\text { requirements. }\end{array}$ & $\begin{array}{l}\text { Needs to make } \\
\text { decisions } \\
\text { 'appropriate' about } \\
\text { moves, locations and } \\
\text { concomitant } \\
\text { relationships, which are } \\
\text { unarticulated and } \\
\text { implicit. }\end{array}$ & $\begin{array}{lr}\text { Participation in and } \\
\text { self-selection } & \text { of } \\
\text { mentoring } & \text { and } \\
\text { coaching } & \text { enables } \\
\text { identity-linked } & \\
\text { sensemaking } & \text { of } \\
\text { ambiguous } & \\
\text { organisational } \\
\text { situations. }\end{array}$ \\
\hline Freedom & $\begin{array}{l}\text { Freedom to develop } \\
\text { technical } \\
\text { competences in } \\
\text { particular areas of } \\
\text { expertise; to make } \\
\text { first (directed) } \\
\text { decisions about next } \\
\text { career destination } \\
\text { and location }\end{array}$ & $\begin{array}{l}\text { Freedom to develop } \\
\text { both } \\
\text { competences technical } \\
\text { increasing freedom to } \\
\text { choose } \\
\text { destination, areas of } \\
\text { expertise to breer } \\
\text { developed }\end{array}$ & $\begin{array}{l}\text { Freedom from tight } \\
\text { development and role } \\
\text { placement structures, } \\
\text { frameworks and } \\
\text { programmes means } \\
\text { self-determination of } \\
\text { individual agent/talent } \\
\text { to make appropriate } \\
\text { choices about their } \\
\text { advancement and } \\
\text { developmental needs. }\end{array}$ \\
\hline
\end{tabular}

